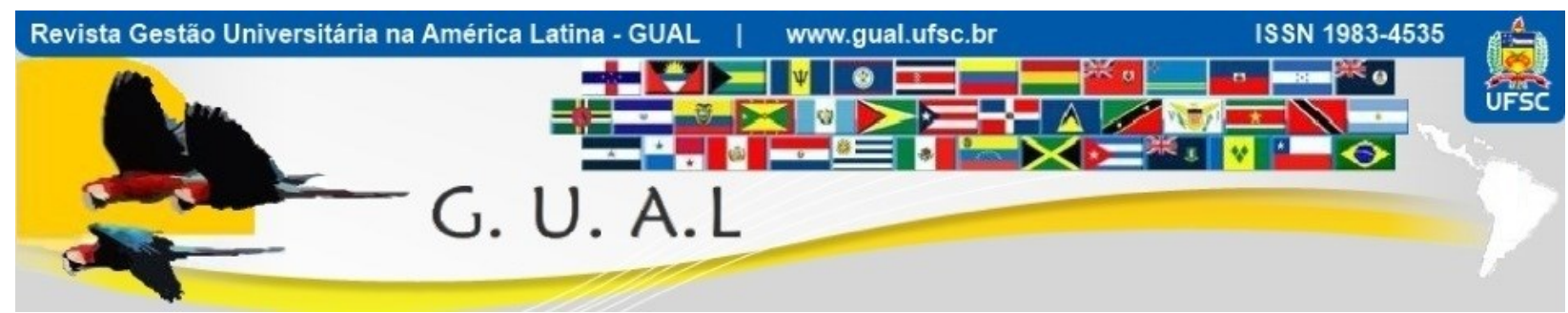

DOI: http://dx.doi.org/10.5007/1983-4535.2018v11n3p86

\title{
SUSTENTABILIDADE: UMA ABORDAGEM ACERCA DAS PERCEPÇÕES DOS ACADÊMICOS DE UMA INSTITUIÇÃO DE ENSINO SUPERIOR DE SANTA CATARINA
}

\author{
SUSTAINABILITY: AN APPROACH ABOUT THE PERCEPTIONS OF AN \\ ACADEMIC INSTITUTION OF HIGHER EDUCATION SANTA CATARINA
}

Silvana Dalmutt Kruger, Doutora Universidade Comunitária da Região de Chapecó - Unochapecó silvanak@unochapeco.edu.br

Cleunice Zanella, Doutora Universidade Comunitária da Região de Chapecó - Unochapecó cleunice@unochapeco.edu.br

Rodrigo Barichello, Doutor Universidade Comunitária da Região de Chapecó - Unochapecó rodrigobarichello@gmail.com

Sérgio Murilo Petri, Doutor Universidade Federal de Santa Catarina - UFSC smpetri@gmail.com

Recebido em 15/outubro/2015

Aprovado em 21/março/2018

Sistema de Avaliação: Double Blind Review 


\title{
RESUMO
}

O estudo teve por objetivo identificar as percepções acerca da temática sustentabilidade pelos acadêmicos de uma instituição de ensino superior localizada no Município de Chapecó- SC. Metodologicamente a pesquisa se caracteriza como descritiva, quanto aos procedimentos de levantamento, com abordagem de cunho quali-quantitativo. Tem como amostra 635 acadêmicos, de 39 cursos superiores de graduação. Os resultados evidenciam que $64,59 \%$ dos respondentes relacionam a temática sustentabilidade com a abordagem de cunho ambiental, $27,86 \%$ relacionam às questões sociais, enquanto $7,54 \%$ ponderam a abordagem econômicofinanceira como preocupação relacionada à temática. Enquanto conceito 55,12\% consideram que a sustentabilidade envolve a preocupação e ações conjuntas que considerem o desempenho econômico, financeiro, ambiental e social, visando garantir melhorias no contexto humano, ambiental e financeiro. Entre as preocupações e objetivos das organizações, $68,19 \%$ consideram o consumo consciente e responsável dos recursos naturais como fator extremamente importante. No contexto das empresas da região Oeste de Santa Catarina, $43,15 \%$ dos respondentes consideram que existe maior enfoque para o desempenho econômico-financeiro, $29,61 \%$ indicam que existe apenas a preocupação com a imagem mercadológica. De modo geral, os resultados evidenciam a importância de discussões e avanços no meio acadêmico, em prol de ações e práticas empresariais que remetam a efetividade da sustentabilidade.

Palavras chave: Sustentabilidade. Desenvolvimento Sustentável. Ensino Superior.

\begin{abstract}
The study aimed to identify perceptions about the sustainability theme by academics from a higher education institution in the municipality of Chapecó- SC. Methodologically the research is characterized as descriptive, as the survey procedures with qualitative and quantitative nature approach. Its sample 635 students, 39 undergraduate courses. The results show that $64.59 \%$ of respondents relate the theme to the sustainability of environmental nature approach, $27.86 \%$ relate to social issues, while $7.54 \%$ are considering the economic and financial approach as concern related to the theme. Concept while $55.12 \%$ believe that sustainability involves concern and joint actions to consider economic, financial, environmental and social performance in order to ensure improvements in human, environmental and financial context. Among the concerns and objectives of the organizations, $68.19 \%$ consider the conscious and responsible consumption of natural resources as extremely important factor. In the context of the companies in the Western region of Santa Catarina, $43.15 \%$ of respondents consider that there is greater focus on the economic and financial performance, $29.61 \%$ indicate that there is only concern with the marketing image. Overall, the results show the importance of discussions and advances in academia, in support of actions and business practices that refer the effectiveness of sustainability.
\end{abstract}

Keywords: Sustainability. Sustainable Development. Higher Education. 


\section{INTRODUÇÃO}

A sustentabilidade tem sido tema de grande interesse entre pesquisadores e empresas, especialmente devido a atenção despertada face às mudanças climáticas causadas pela ação predatória do homem no meio ambiente causando uma emergência planetária, reconhecendo que o preço de fatores como o meio ambiente, o impacto sobre as comunidades e a longevidade dos funcionários pode significar uma visão mais ampla de sustentar a lucratividade da empresa ao longo do tempo (COSTA; SANTOS, 2009).

A internalização de princípios sustentáveis nas estratégias de negócios das organizações torna-se um desafio pelo fato de que ocorrem, muitas vezes, conflitos em relação aos objetivos. Todavia, tornam-se cada vez mais necessários diante das pressões da sociedade e exigências legais por responsabilidades socioambientais destas empresas. As organizações, independentemente do seu porte, devem ter claro que se encontram diante de uma nova realidade mundial, na qual pensar ambientalmente e socialmente, sem perder de vista o foco econômico, além de ser uma atitude responsável, passa a ser algo bem visto pelos consumidores, resultando em ganhos competitivos e, em muitos casos, garantia de sobrevivência no mercado (BACALLAN, 2000; BARIN-CRUZ; PEDROZO; MARTINET, 2007).

Neste sentido, o contexto organizacional no qual as entidades estão inseridas inclui as preocupações com o meio ambiente e as questões sociais, tendo em vista que a sociedade de forma geral e os stakeholders passaram a observar as ações e práticas sociais e ambientais das organizações. Surgem então as inquietações em relação ao desenvolvimento e o meio ambiente, exigindo das entidades o compromisso com as exigências do mercado e o desempenho econômico, mas também com alternativas em prol do desenvolvimento sustentável (TREVISAN et al., 2008; CAMPOS, ESTIVALETE E MACHADO, 2008; KRUGER et al., 2013).

O conceito de desenvolvimento sustentável traz mudanças nas relações entre a humanidade e a natureza, distanciando-se da visão do capitalismo, reforçando as discussões que o conhecimento humano e a tecnologia não podem transpor os obstáculos relacionados à natureza e ao ambiente. O crescimento econômico não possibilitou que a pobreza fosse superada, tampouco inibiu os problemas ambientais e o consumo insustentáveis, gerando questionamentos quando o desenvolvimento econômico não ocorre a partir das boas práticas 


\section{SUSTENTABILIDADE: UMA ABORDAGEM ACERCA DAS PERCEPÇÕES DOS ACADÊMICOS DE UMA INSTITUIÇÃO DE ENSINO SUPERIOR DE SANTA CATARINA \\ DOI: http://dx.doi.org/10.5007/1983-4535.2018v11n3p86}

de gerenciamento dos recursos naturais e do desenvolvimento sustentável (MEBRATU, 1998; KRUGER et al., 2013).

Além da preocupação com o consumo insustentável, conforme Melo e Cândido (2013), torna-se necessário a realização de estudos e pesquisas que considerem os aspectos da sustentabilidade para as práticas desenvolvidas também no meio rural, tendo em vista a agricultura ser a base fundamental para o desenvolvimento econômico da sociedade, e na construção de uma sociedade sustentável e íntegra em todos os seus aspectos.

Albarello (2011) enfatiza a necessidade do despertar de um pensamento produtivo, no qual todos os atores envolvidos sejam respeitados e inseridos no modelo socioeconômico mundial, tendo em vista que a sustentabilidade envolve à preservação e à conservação dos recursos que são utilizados no âmbito social, cultural, econômico e ambiental, pois a sustentabilidade tem direta relação com todas as etapas da produção e seu desenvolvimento.

O conceito de sustentabilidade deve ser avaliado de forma abrangente. Segundo Bacha, Santos e Schaun (2010), as análises deixaram transparecer diferentes correntes de pensamento em relação aos enfoques de sustentabilidade bem como as contradições e ambiguidades da expressão desenvolvimento sustentável. De maneira geral as definições procuram integrar viabilidade econômica com prudência ecológica e justiça social, nas três dimensões conhecidas como Tripple Bottom Line (ELKINGTON, 1998; ALMEIDA, 2002).

Salienta-se, no entanto, que o tema sustentabilidade, apesar de atual e gerar constantes discussões na mídia, instituições e comunidade, muitas vezes pode não é entendido no seu conceito mais completo, que considera tanto questões ambientais, financeiras e sociais, que compreendem as dimensões do Tripple Bottom Line, citadas por Elkington (1998) e Almeida (2002), tratando da viabilidade econômica com prudência ecológica e justiça social.

Neste sentido, este estudo procura identificar as percepções acerca da temática sustentabilidade pelos acadêmicos de uma instituição de ensino superior localizada no Município de Chapecó, Estado de Santa Catarina. Visa identificar qual o entendimento do tema sustentabilidade, bem como promover a reflexão sobre o papel das instituições de ensino neste processo, assim como observar como os estudantes percebem as ações das organizações empresariais quanto à sustentabilidade.

Zamberlan et al. (2015), destacam que a sustentabilidade está presente em diversas matrizes curriculares dos mais variados cursos superiores e técnicos de formação profissional. Desta forma a formação de professores e a necessidade de preparação dos alunos para uma 
sociedade global, exige a compreensão e discussões acerca do contexto da temática sustentabilidade. Ainda, destaca que a preocupação em aliar o desenvolvimento econômico e social com a adequada preservação dos recursos naturais, tornou-se objeto de pesquisas em diversas áreas do conhecimento, pois todas estão inseridas num mesmo contexto.

Justifica-se a relevância do estudo ponderando a importância de ações contínuas em prol da sustentabilidade, especialmente no contexto do ambiente empresarial, visando melhorias de curto e longo prazos, no âmbito dos efeitos e danos causados pelas atividades empresarial ao meio ambiente e a sociedade de modo geral, tendo em vista que muitas vezes os objetivos organizacionais estão focados apenas no desempenho econômico-financeiro. Neste sentido, pretende-se inserir no ambiente acadêmico a importância desta reflexão que pondere um equilíbrio entre as variáveis ambiental, social e econômico-financeira.

\section{ASPECTOS CONTEXTUAIS DA SUSTENTABILIDADE}

Ao tratar da temática sustentabilidade, recorre-se ao Relatório de Bruntland - Nosso Futuro Comum, resultado do encontro da Comissão Mundial sobre Meio Ambiente e Desenvolvimento, a partir dos esforços da Organização das Nações Unidas - ONU em 1983, sendo a primeira referência sobre sustentabilidade, considerado um marco na discussão deste tema ao considerar o desenvolvimento sustentável como a capacidade de atender as necessidades do presente, sem comprometer as gerações futuras. Outro marco na discussão da sustentabilidade se refere à II Conferência Mundial sobre o Meio Ambiente (Rio-92), com a elaboração de um documento oficial, a Agenda 21, que além de práticas e alternativas em prol do meio ambiente, enfatiza a necessidade do desenvolvimento de indicadores de sustentabilidade, estes devendo ser elaborados no contexto de cada país, considerando as suas realidades distintas (MARZALL; ALMEIDA, 2000).

Desenvolvimento Sustentável pode ser definido como um modelo de desenvolvimento que "atende as necessidades do presente sem comprometer a habilidade das futuras gerações em atender suas próprias necessidades" (WCED, 1987, p. 43). Com o propósito de estabelecer princípios que garantam a prosperidade econômica aliada à integridade ambiental e equidade social, visando nortear as ações empresariais e direcionar o desenvolvimento econômico em prol do desenvolvimento sustentável.

Não é possível tratar do tema sustentabilidade sem relacioná-lo ao tema desenvolvimento, pois, segundo Mota (2001), o desenvolvimento pode ser classificado em 
três dimensões: (i) o desenvolvimento como progresso; (ii) o desenvolvimento como bem estar social e, (iii) o desenvolvimento sustentável, voltado as relações entre o homem, a natureza e os processos de produção e consumo. Verona (2008) caracteriza a sustentabilidade como parte multidimensional de um sistema socioambiental, que deve considerar o contexto social em que estão inseridas as atividades, para a avaliação e a construção de alternativas visando o desenvolvimento sustentável.

As discussões propostas por Elkington (1998), ponderam a sustentação de três pilares para a temática da sustentabilidade, denominado o tripé da sustentabilidade (Triple Botton Line), (i) o econômico, (ii) o social e (iii) o ambiental.

Costa e Santos (2009) salientam que embora em muitas situações parte-se da sustentabilidade ambiental para se ampliar o debate, a sustentabilidade social, política, cultural, como também a financeira, são sentidos mais amplos da abordagem adequada da temática, especialmente no contexto das organizações. Nesse sentido, a sustentabilidade compreende uma multidimensionalidade e complexidade que envolve "recursos financeiros, engajamento político, uma missão bem definida, condução ética, diálogo com os vários setores da sociedade, efetivação de parcerias, produção e socialização de conhecimento, afetividade e respeito nas relações interpessoais, bem como coragem para construir ações coletivas" (COSTA; SANTOS, 2009, p.118).

De acordo com Anglade (1999), as atividades desenvolvidas no meio empresarial ou rural, como qualquer outra atividade humana, para garantir sua sustentabilidade e a continuidade do negócio, deve considerar simultaneamente, as três dimensões: (i) econômica, (ii) ambiental e (iii) social. Neste sentido, pode-se dizer que deve ser uma atividade economicamente viável (rentável financeiramente), ecologicamente saudável (atender os aspectos ambientais adequados), e socialmente equitativa (agregar benefícios para a sociedade, sem comprometer recursos futuros).

Para Claro, Claro e Amâncio (2008) as empresas têm encontrado dificuldade em associar discursos e práticas gerenciais à interpretação de sustentabilidade, embora o termo esteja cada vez mais presente no ambiente empresarial, assim a sustentabilidade e o desenvolvimento sustentável seriam terminologias equivalentes, ponderando a visão de longo prazo, uma vez que os interesses das futuras gerações devem ser analisados.

Marzall e Almeida (2000), destacam a sustentabilidade como desenvolvimento econômico como sinônimo de sustentabilidade social, que depende de ações coordenadas de 
cooperação para reverter o quadro de concentração de renda em determinadas regiões ou países. Para Trigo, Lima e Oliveira (2014), a responsabilidade social é uma das condições para garantir sustentabilidade das instituições. Os conceitos de governança corporativa e responsabilidade social estão integrados na medida em que se procura estabelecer padrões de conduta das empresas com seus stakeholders.

Em termos econômicos a sustentabilidade prevê que as organizações devem ser economicamente viáveis, face ao seu papel na sociedade e que deve ser cumprido levando-se em consideração o aspecto da rentabilidade. Do ponto de vista social, a organização deveria proporcionar boas condições de trabalho e em termos ambientais, a empresa deveria pautar-se pela ecoeficiência dos seus processos produtivos, oferecendo condições para o desenvolvimento de uma cultura ambiental organizacional, adotando uma postura ética e com responsabilidade ambiental. De modo geral, o crescente interesse pela sustentabilidade tem apresentado impactos nas estratégias das empresas, estas são cada vez mais cobradas no contexto de evidenciarem ações de cunho sócio-ambiental e sustentável. Tal cobrança é feita tanto pela sociedade como pelos seus clientes corporativos, pelos governos, dentre outros stakeholders (MEBRATU, 1998).

Neste sentido, apesar do inicial ceticismo, é cada vez maior a integração de princípios de sustentabilidade às estratégias de negócios e de competitividade. É crescente a comprovação de que resultados positivos em termos de melhoria de imagem, competitividade e redução de custos são obtidos com a gestão de questões socioambientais nos processos organizacionais. A influência da sustentabilidade sobre as questões gerenciais se confirma a partir das discussões de Bansal (2005); Russo e Founts (1997), ao afirmarem que a razão pela qual as organizações aplicam as questões ambientais e sociais em suas estratégias, está relacionada à melhoria de seus recursos e no aumento das capacidades competitivas, surgindo oportunidades para diferenciação de produtos baseados nas dimensões avaliadas e também na construção de uma reputação corporativa frente à mídia e aos órgãos governamentais.

As instituições desempenham um importante papel no estabelecimento do Desenvolvimento Sustentável no ambiente organizacional, por possuírem recursos financeiros, conhecimento tecnológico e capacidade institucional para implementar soluções ecológicas, neste sentido a a partir do momento em que as organizações levam em conta as questões ambientais em seus contextos, devem estabelecer e desenvolver estratégias focadas para estes aspectos e desenvolver ainda programas de gerenciamento ambiental. Neste 
sentido, as práticas sustentáveis integradas aos negócios organizacionais que deveriam passar por etapas gerenciadas, iniciando por as ações que devem advir das estratégias de negócios, passando a ser aplicadas junto às atividades da organização com o monitoramento do desempenho de tais atividades bem como com a avaliação dos stakeholders (EPSTEIN; ROY, 2001; BANSAL, 2005).

Kruger et al. (2013), destaca que as preocupações com a responsabilidade social e ambiental deve ser parte do processo gestão nas diversas instâncias ou setores das instituições, visando que sejam considerados além dos efeitos econômico-financeiros, os impactos ambientais, no intuito de refletir o compromisso institucional com o dever ético e responsável que todas as entidades deveriam atender.

Trigo, Lima e Oliveira (2014), destacam que as instituições de ensino superior, tornam-se as principais responsáveis pela propagação do conhecimento na sociedade, tendo em vista seu papel de formação dos profissionais que assumem posições de decisão nas empresas, neste sentido, têm papel fundamental no desenvolvimento sociedades sustentáveis, devendo ser modelos de sustentabilidade.

Neste contexto Zamberlan et al. (2015), indicam que a educação ambiental torna-se uma forma de se atingir a compreensão acerca da sustentabilidade, bem como tal tema deveria ser obrigatório do currículo dos cursos, visando atingir soluções práticas de economia dos recursos renováveis e não renováveis junto à sociedade. Neste sentido, destaca a preocupação com a mobilização de novas posturas de pais, alunos, professores e da comunidade, visando evitar o esgotamento ambiental. A mudança de postura vai além da fala, é preciso prática, e tal prática deveria estar presente nas salas de aula, a fim de iniciar uma cultura formativa em prol da sustentabilidade, a qual deve estar alicerçada em seus três pilares: o social, o econômico e o ambiental.

\section{PROCEDIMENTOS METODOLÓGICOS}

Metodologicamente a pesquisa se caracteriza como descritiva, quanto aos procedimentos de levantamento ou survey, com abordagem de cunho quali-quantitativo.

A pesquisa foi realizada por meio de um questionário aplicado para acadêmicos graduandos nas áreas de Ciências Sociais e Aplicadas, Humanas e Jurídicas, Exatas e Ambientais e Ciências da Saúde. O instrumento foi desenvolvido e enviado por meio eletrônico (google.docs), a todos os acadêmicos da Universidade Comunitária da Região de 
Chapecó- Unochapecó, Instituição de Ensino Superior (IES), localizada na região Oeste do Estado de Santa Catarina. O instrumento foi enviado para cerca de 6.900 estudantes regularmente matriculados nos 42 cursos superiores da IES, no período de junho e julho de 2014.

O questionário foi composto por 9 questões, visando identificar inicialmente as características dos respondentes e posteriormente as percepções destes acerca da temática sustentabilidade. O questionamento considerou as seguintes abordagens:

a) Indicação do curso de graduação vinculado;

b) Indicação da idade;

c) Indicação do sexo;

d) Percepção acerca da temática sustentabilidade;

e) Percepção quanto às preocupações e objetivos das organizações empresariais;

f) Compreensão sobre o tema e conceito de sustentabilidade;

g) Percepção quanto à preocupação das empresas com a sustentabilidade;

h) Em que medida as empresas demonstram preocupação com a sustentabilidade;

i) Em que medida a discussão sobre sustentabilidade ocorre no curso de graduação.

A amostra final de respondentes é composta por 635 acadêmicos, destes $66,80 \%$ são do sexo feminino e $33,20 \%$ do sexo masculino, entre os 39 cursos participantes da pesquisa destacam-se Administração (14,17\%); Direito (13,07\%); Ciências Contábeis (11,34\%); e outros 36 cursos apresentam percentuais inferiores a 5\% do total das respostas obtidas pela amostra, a exemplo de Engenharia Civil (4,90\%); Arquitetura e Urbanismo (4,60\%); Ciências Biológicas (3,90\%), Psicologia (3,80\%), Agronomia (3,10\%) entre outros.

A partir das respostas obtidas, a análise dos dados utiliza-se de Tabelas para identificar a frequência absoluta e relativa, para interpretação dos resultados, visando atingir o objetivo proposto pelo estudo e contribuir com os resultados da pesquisa.

\section{ANÁLISE E INTERPRETAÇÃO DOS RESULTADOS}

A partir do questionário aplicado, apresenta-se nesta seção a análise das respostas obtidas. Inicialmente caracteriza-se os respondentes como $66,80 \%$ do sexo feminino e $33,20 \%$ do sexo masculino. Com relação a faixa etária, verifica-se que a maioria possui idade de até 25 anos, como observa-se na Tabela 1. 


\section{SUSTENTABILIDADE: UMA ABORDAGEM ACERCA DAS PERCEPÇÕES DOS ACADÊMICOS DE UMA INSTITUIÇÃO DE ENSINO SUPERIOR DE SANTA CATARINA \\ DOI: http://dx.doi.org/10.5007/1983-4535.2018v11n3p86}

Tabela 1 Idade dos entrevistados

\begin{tabular}{l|c|c}
\hline \multicolumn{1}{c|}{ Faixa etária } & Frequência absoluta & Frequência relativa \\
\hline Até 20 anos & 211 & 33,23 \\
\hline De 20 a 25 anos & 231 & 36,38 \\
\hline De 26 a 30 anos & 91 & 14,33 \\
\hline De 31 a 35 anos & 40 & 6,30 \\
\hline De 36 a 40 anos & 28 & 4,41 \\
\hline Acima de 40 anos & 34 & 5,35 \\
\hline Total & 635 & 100,00 \\
\hline
\end{tabular}

Fonte: Dados da pesquisa

Observa-se que 69,61\% dos respondentes possuem idade de até 25 anos, enquanto outros $14,33 \%$ entre 26 e 30 anos e 16,06\% acima de 31 anos. Destaca-se neste sentido a predominância de jovens estudantes, cursando possivelmente a primeira graduação.

A partir da quarta questão, o instrumento de coleta de dados questionou os respondentes acerca da temática sustentabilidade. Inicialmente foram questionados com relação a sua percepção a respeito da temática em questão. A Tabela 2 apresenta a relação do conceito relacionado ao tema.

A Tabela 2 contempla temas que remetem ao tripé da sustentabilidade, ou seja ao conceito que considera as variáveis: (i) econômica, (ii) ambiental e (iii) social (ANGLADE, 1999). Embora se pode observar que a questão permitia escolher até 6 alternativas relacionadas a sustentabilidade, totalizando 3.022 respostas, observa-se que a ênfase ambiental prevalece entre as respostas, com destaque para a responsabilidade ambiental indicada por $80,80 \%$ dos respondentes, a preocupação com os recursos naturais/ambientais 51,50\%; tecnologias limpas 45,80\%; energia renovável indicada por $43,00 \%$ dos respondentes. A ênfase social aparece indicada pela responsabilidade social de $43,90 \%$ dos respondentes, seguida pela preocupação com os problemas sociais indicada por $24,90 \%$. A ênfase econômico-financeira é indicada por $13,40 \%$ dos respondentes que consideram o desempenho econômico-financeiro e outros $6,80 \%$ que citam o desempenho financeiro.

Neste sentido a partir das respostas obtidas, verificou-se maior ênfase por parte dos respondentes nas questões relacionadas ao meio ambiente, que somadas totalizam $64,59 \%$ da abordagem indicada pelos respondentes. A Tabela 3 sintetiza as escolhas dos respondentes. 


\section{SUSTENTABILIDADE: UMA ABORDAGEM ACERCA DAS PERCEPCÕES DOS ACADÊMICOS DE UMA INSTITUIÇÃO DE ENSINO SUPERIOR DE SANTA CATARINA DOI: http://dx.doi.org/10.5007/1983-4535.2018v11n3p86}

Tabela 2 Percepção sobre a temática sustentabilidade

\begin{tabular}{l|c|c}
\hline \multicolumn{1}{c|}{ Alternativas * } & $\begin{array}{c}\text { Frequência } \\
\text { absoluta }\end{array}$ & Frequência relativa \\
\hline Responsabilidade ambiental & 513 & 80,80 \\
\hline Recursos naturais/ambientais & 327 & 51,50 \\
\hline Tecnologias limpas & 291 & 45,80 \\
\hline Responsabilidade social & 279 & 43,90 \\
\hline Energia renovável & 273 & 43,00 \\
\hline Economia de recursos materiais & 222 & 35,00 \\
\hline Preocupação com os problemas sociais & 158 & 24,90 \\
\hline Inovação & 134 & 21,10 \\
\hline Melhoria da qualidade de vida dos trabalhadores & 117 & 18,40 \\
\hline Necessidades humanas & 117 & 18,40 \\
\hline Melhorias de processos & 99 & 15,60 \\
\hline Políticas públicas & 93 & 14,06 \\
\hline Degradação ambiental & 93 & 14,06 \\
\hline Desempenho econômico-financeiro & 85 & 13,40 \\
\hline Justiça social e desenvolvimento comunitário & 78 & 12,30 \\
\hline Desempenho financeiro & 43 & 6,80 \\
\hline Retorno sobre o investimento & 37 & 5,80 \\
\hline Desempenho econômico & 33 & 5,20 \\
\hline Rentabilidade do negócio & 30 & 4,70 \\
\hline Total & $\mathbf{3 . 0 2 2}$ & \\
\hline
\end{tabular}

*Nesta questão o respondente poderia escolher até seis alternativas Fonte: Dados da pesquisa

Tabela 3 Percepção sobre a abordagem da temática sustentabilidade

\begin{tabular}{l|c|c}
\hline \multicolumn{1}{c|}{ Contexto da abordagem } & $\begin{array}{c}\text { Frequência } \\
\text { absoluta }\end{array}$ & $\begin{array}{c}\text { Frequência } \\
\text { relativa }\end{array}$ \\
\hline $\begin{array}{l}\text { Abordagem ambiental: } \\
\begin{array}{l}\text { Responsabilidade ambiental; Recursos naturais/ambientais; } \\
\text { Tecnologias limpas; Energia renovável; Economia de recursos } \\
\text { materiais; Degradação ambiental; Inovação; Melhorias de } \\
\text { processos. }\end{array}\end{array}$ & 1.952 & 64,59 \\
\hline $\begin{array}{l}\text { Abordagem social: } \\
\text { Responsabilidade social; Preocupação com os problemas sociais; }\end{array}$ & 842 & 27,86 \\
$\begin{array}{l}\text { Melhoria da qualidade de vida dos trabalhadores; Necessidades } \\
\text { humanas; Políticas públicas; Justiça social e desenvolvimento } \\
\text { comunitário. }\end{array}$ & & \\
\hline $\begin{array}{l}\text { Abordagem econômico-financeira: } \\
\text { Desempenho econômico-financeiro; Rentabilidade do negócio; } \\
\text { Desempenho econômico; Desempenho financeiro; Retorno sobre } \\
\text { o investimento. }\end{array}$ & 228 & 7,54 \\
\hline Total & $\mathbf{3 . 0 2 2}$ & $\mathbf{1 0 0 , 0 0}$ \\
\hline
\end{tabular}

Fonte: Dados da pesquisa

Observa-se na síntese das respostas da Tabela 3 que a ênfase da abordagem ambiental prevalece na interpretação acerca da sustentabilidade. Sendo que $64,59 \%$ dos respondentes 
relacionam a sustentabilidade com responsabilidade ambiental, que representa $16,88 \%$ do total de respostas, seguido de recursos naturais/ambientais com 10,82\%, tecnologias limpas com 9,63\%, energia renovável com 9,03\%, economia dos recursos naturais com 7,35\%, inovação com 4,43\%, melhoria dos processos 3,28\% e degradação ambiental com 3,08\%.

Observou-se na sequência, questões relacionadas a sustentabilidade como fator social, totalizando $27,86 \%$ das respostas, sendo responsabilidade social com 9,23\%, preocupação com os problemas sociais com 5,23\%, melhoria da qualidade de vida dos trabalhadores e necessidades humanas com 3,87\% respectivamente, políticas públicas com 3,08\% e justiça social e desenvolvimento comunitário com $2,58 \%$.

Por fim, os respondentes destacaram questões relacionadas à sustentabilidade financeira que, somadas, representam 7,54\% das respostas, sendo desempenho econômicofinanceiro com $2,81 \%$, desempenho financeiro com $1,42 \%$, retorno sobre o investimento com 1,22\%, desempenho econômico com 1,09\% e rentabilidade do negócio com 0,99\%.

De modo geral, percebe-se, que ao tratar da temática sustentabilidade a maioria dos estudantes desta instituição, ou seja, 64,59\% a relacionam ao meio ambiente (ênfase ambiental), seguido de $27,86 \%$ que relacionam sustentabilidade às questões sociais, enquanto somente 7,54\% dos respondentes ponderam a abordagem econômico-financeira como preocupação relacionada à temática sustentabilidade.

Na sequência os respondentes foram questionados sobre sua compreensão em relação as preocupações e objetivos das organizações empresariais de modo geral. Os resultados estão apresentados na Tabela 4:

Observa-se na Tabela 4 que os respondentes poderiam indicar numa relação de 1 a 5 , sendo 1 para nada importante e 5 para extremamente importante. Cada alternativa possibilidade tal indicação de importância. Percebe-se que 68,19\% dos respondentes consideram o consumo consciente e responsável dos recursos naturais como fator extremamente importante entre as preocupações e objetivos das organizações empresariais, seguido da qualidade dos produtos/serviços indicada por $68,03 \% ; 64,25 \%$ indicam o uso de tecnologias limpas e economia de recursos materiais; $60,47 \%$ o atendimento das necessidades dos clientes $51,34 \%$ indicam a preocupação com a inovação de processos, produtos e serviços; 48,98\% respectivamente indicam a preocupação com o bem estar social e o desenvolvimento de ações voltadas aos problemas sociais e ao comunitário. 


\section{SUSTENTABILIDADE: UMA ABORDAGEM ACERCA DAS PERCEPÇÕES DOS ACADÊMICOS DE UMA INSTITUIÇÃO DE ENSINO SUPERIOR DE SANTA CATARINA \\ DOI: http://dx.doi.org/10.5007/1983-4535.2018v11n3p86}

Tabela 4 Preocupações e objetivos das organizações empresariais de modo geral

\begin{tabular}{l|c|c|c|c|c}
\hline \multicolumn{1}{c|}{ Alternativas * } & 1 & 2 & 3 & 4 & 5 \\
\hline Consumo consciente e responsável dos recursos naturais & 1,42 & 4,25 & 11,18 & 14,96 & 68,19 \\
\hline Qualidade dos produtos/serviços & 0,79 & 0,94 & 14,49 & 15,75 & 68,03 \\
\hline Uso de tecnologias limpas e economia de recursos materiais & 2,05 & 3,94 & 13,23 & 16,54 & 64,25 \\
\hline Atender as necessidades dos clientes & 1,10 & 2,36 & 17,80 & 18,27 & 60,47 \\
\hline Inovação de processos, produtos e serviços & 1,26 & 2,99 & 16,54 & 27,87 & 51,34 \\
\hline Bem estar social & 1,10 & 2,83 & 19,69 & 27,40 & 48,98 \\
\hline $\begin{array}{l}\text { Desenvolvimento de ações voltadas aos problemas sociais e } \\
\text { ao comunitário }\end{array}$ & 3,15 & 4,57 & 17,95 & 25,35 & 48,98 \\
\hline Retorno financeiro sobre o investimento & 0,47 & 2,36 & 23,31 & 27,40 & 46,46 \\
\hline Desempenho econômico e financeiro & 0,16 & 2,05 & 23,78 & 27,87 & 46,14 \\
\hline Rentabilidade do negócio & 0,47 & 2,83 & 23,62 & 29,76 & 43,31 \\
\hline Lucratividade & 0,94 & 3,46 & 26,93 & 26,46 & 42,20 \\
\hline Continuidade & 0,94 & 3,78 & 27,40 & 29,13 & 38,74 \\
\hline
\end{tabular}

Legenda*: (1) Nada importante; (2) Pouco importante; (3) Importante; (4) Muito importante; (5) Extremamente importante.

Fonte: Dados da pesquisa

Novamente as variáveis com abordagem de ênfase econômico-financeira aparecem indicadas com menor relevância, na percepção dos respondentes as variáveis ambientais e sociais possuem relevância e devem ser as principais preocupações dos gestores em relação aos objetivos das organizações empresariais.

Visando contribuir e resgatar de forma geral as percepções dos respondentes em relação a compreensão da temática sustentabilidade, relacionou-se os seguintes conceitos apresentados na Tabela 5 .

Observa-se na Tabela 5 a relação de alternativas apresentadas aos acadêmicos da IES pesquisada. As respostas possibilitavam a abordagem sob o enfoque ambiental $(39,06 \%$ dos respondentes a indicaram); a abordagem social (3,78\% dos respondentes a consideraram); a abordagem econômico-financeira (apenas 2,05\% dos respondentes a indicaram); e a primeira alternativa apresentada na Tabela 5 contemplava a abordagem da sustentabilidade sob os aspectos ambiental, social e econômico-financeiro, sendo considerada a melhor compreensão sobre a temática para $55,12 \%$ dos respondentes.

Pode-se perceber que a ênfase sob o enfoque apenas de cunho ambiental também prevaleceu nesta questão, reforçando as percepções anteriormente indicadas nas questões anteriores (Tabelas 2 a 4). 


\section{SUSTENTABILIDADE: UMA ABORDAGEM ACERCA DAS PERCEPÇÕES DOS ACADÊMICOS DE UMA INSTITUIÇÃO DE ENSINO SUPERIOR DE SANTA CATARINA \\ DOI: http://dx.doi.org/10.5007/1983-4535.2018v11n3p86}

Tabela 5 Compreensão relacionada à temática sustentabilidade

\begin{tabular}{l|c|c}
\hline \multicolumn{1}{c|}{ Alternativa } & $\begin{array}{c}\text { Frequência } \\
\text { absoluta }\end{array}$ & $\begin{array}{c}\text { Frequência } \\
\text { relativa }\end{array}$ \\
\hline $\begin{array}{l}\text { A sustentabilidade envolve a preocupação e ações conjuntas que } \\
\text { considerem o desempenho econômico, financeiro, ambiental e social, } \\
\text { visando garantir melhorias no contexto humano, ambiental e financeiro. }\end{array}$ & 350 & 55,12 \\
\hline $\begin{array}{l}\text { A sustentabilidade envolve o consumo consciente dos recursos naturais } \\
\text { (energia, água, solo, ar, vida vegetal, etc.), sem comprometer as } \\
\text { necessidades das gerações futuras. }\end{array}$ & 248 & 39,06 \\
\hline $\begin{array}{l}\text { A sustentabilidade envolve questões relacionadas a justiça social e o } \\
\text { desenvolvimento comunitário, tais como as relaçôes com os } \\
\text { trabalhadores, o bem estar humano e qualidade de vida. }\end{array}$ & 24 & 3,78 \\
\hline $\begin{array}{l}\text { A sustentabilidade envolve o planejamento financeiro da empresa, de } \\
\text { modo que o desempenho econômico seja condição para a empresa se } \\
\text { manter competitiva no mercado. }\end{array}$ & 13 & 2,05 \\
\hline Total & $\mathbf{6 3 5}$ & $\mathbf{1 0 0 , 0 0}$ \\
\hline
\end{tabular}

Fonte: Dados da pesquisa

Na sequência os respondentes foram questionados quanto a preocupação das empresas da região Oeste de Santa Catarina com relação à sustentabilidade. Do total de respostas, 448 ou $70,60 \%$ dos respondentes consideram que as empresas estão parcialmente preocupadas com a sustentabilidade, 155 ou $24,40 \%$ dos respondentes, consideram que as empresas não estão preocupadas com a sustentabilidade, e outros 32 respondentes ou $5 \%$ da amostra consideram que as empresas estão preocupadas com a sustentabilidade.

Neste sentido, questionou-se acerca das preocupações das empresas da região Oeste de Santa Catarina com a sustentabilidade. Os respondentes foram solicitados a indicar em que medida as empresas estão preocupadas com a sustentabilidade, conforme apresenta a Tabela 6 a seguir.

Observa-se que a abordagem que considera a preocupação com o viés econômicofinanceiro, ambiental e social, é percebida por apenas $17,17 \%$ dos respondentes. No entanto, outros $14,96 \%$ indicam que não percebem a preocupação por parte das empresas com a sustentabilidade. Para 43,15\% dos respondentes existe maior enfoque para o desempenho econômico-financeiro por parte das empresas da região, 29,61\% indicam que existe apenas a preocupação com a imagem mercadológica e apenas 14,01\% dos respondentes indicam que existe preocupação com o meio ambiente e com o uso consciente dos recursos naturais. 


\section{SUSTENTABILIDADE: UMA ABORDAGEM ACERCA DAS PERCEPÇÕES DOS ACADÊMICOS DE UMA INSTITUIÇÃO DE ENSINO SUPERIOR DE SANTA CATARINA \\ DOI: http://dx.doi.org/10.5007/1983-4535.2018v11n3p86}

Tabela 6 Preocupação das empresas da região Oeste de Santa Catarina com a sustentabilidade

\begin{tabular}{l|c|c}
\hline \multicolumn{1}{c|}{ Alternativa* $^{*}$} & $\begin{array}{c}\text { Frequência } \\
\text { absoluta }\end{array}$ & $\begin{array}{c}\text { Frequência } \\
\text { relativa }\end{array}$ \\
\hline Existe maior enfoque para o desempenho econômico-financeiro & 274 & 43,15 \\
\hline Existe apenas a preocupação com a imagem mercadológica & 188 & 29,61 \\
\hline Existe preocupação com o viés econômico-financeiro, ambiental e social & 109 & 17,17 \\
\hline Não percebo preocupação por parte das empresas & 95 & 14,96 \\
\hline $\begin{array}{l}\text { Existe preocupação com o meio ambiente e com o uso consciente dos } \\
\text { recursos naturais }\end{array}$ & 89 & 14,01 \\
\hline $\begin{array}{l}\text { Existe preocupação com a qualidade de vida dos trabalhadores e do } \\
\text { impacto da atuação da empresa na comunidade }\end{array}$ & 75 & 11,81 \\
\hline Total & $\mathbf{8 3 0}$ & 0.000 \\
\hline
\end{tabular}

*Nesta questão o respondente poderia indicar mais de uma alternativa

Fonte: Dados da pesquisa

Tais ponderações servem de alerta para as empresas da região, visando a melhoria de ações e práticas que remetam a efetividade do contexto sustentável nas relações empresariais, não somente para a melhoria da imagem institucional, mas principalmente para agregar ações concretas em prol do meio ambiente e da comunidade.

O último questionamento aos respondentes se referiu as discussões da temática sustentabilidade no decorrer do curso de graduação aos quais estão matriculados, conforme evidencia a Tabela 7, visando demonstrar se ocorrem discussões acerca da temática em disciplinas específicas ou outras atividades, tais como semanas acadêmicas, ciclos de estudos, etc., dos cursos superiores de graduação.

Tabela 7 Em que medida a discussão sobre sustentabilidade ocorre no seu curso

\begin{tabular}{l|c|c}
\hline \multicolumn{1}{c|}{ Alternativa } & $\begin{array}{c}\text { Frequência } \\
\text { absoluta }\end{array}$ & $\begin{array}{c}\text { Frequência } \\
\text { relativa }\end{array}$ \\
\hline Entre várias disciplinas /interdisciplinariedade & 200 & 31,50 \\
Não há, ou ainda não ocorreu & 162 & 25,51 \\
Semanas acadêmicas, debates, ciclos de estudos, palestras, etc. & 136 & 21,42 \\
Em disciplina específica & 125 & 19,69 \\
Não me sinto apto a responder & 99 & 15,59 \\
\hline Total & $\mathbf{7 2 2}$ & \\
\hline
\end{tabular}

Fonte: Dados da pesquisa

Observa-se na Tabela 7 que embora alguns acadêmicos participantes da pesquisa possam estar ainda em períodos iniciais de seus cursos, 31,50\% dos respondentes indicam que existe a discussão acerca da temática em diversas disciplinas; $21,42 \%$ indicaram que o debate 
ocorreu em semanas acadêmicas ou evento relacionado; e ainda 19,69\% indicam que existe uma disciplina específica no curso que trata sobre o tema.

Destaca-se neste sentido que a amostra pesquisada refere-se a 39 cursos de graduação, e tais resultados revelam de modo geral a importância de discussões sobre a temática, especialmente quanto à adequada compreensão sobre o contexto da sustentabilidade, ponderando o viés ambiental, social e econômico-financeiro.

\section{CONCLUSÕES}

O estudo teve por objetivo identificar as percepções acerca da temática sustentabilidade pelos acadêmicos de uma instituição de ensino superior localizada no Município de Chapecó-SC. Por meio de um questionário foi possível coletar as respostas de 635 acadêmicos de 39 cursos superiores de graduação distintos.

Os resultados evidenciam inicialmente as percepções quanto ao contexto da sustentabilidade, relevando que $64,59 \%$ dos respondentes relacionam a temática sustentabilidade com a abordagem ambiental, 27,86\% relacionam às questões sociais, e apenas 7,54\% dos respondentes indicaram a abordagem econômico-financeira como preocupação relacionada à temática sustentabilidade. Nesta primeira análise observa-se o apelo do contexto ambiental como principal relação de conceito com a temática sustentabilidade pelos respondentes do estudo.

Posteriormente quando sugeriu-se um conceito para análise, 55,12\% dos respondentes consideraram que a "sustentabilidade envolve a preocupação e ações conjuntas que considerem o desempenho econômico, financeiro, ambiental e social, visando garantir melhorias no contexto humano, ambiental e financeiro". Nesta interpretação observou-se que houve evolução no conceito proposto, equalizando a interpretação acerca da temática.

No entanto, posteriormente quando questionados acerca das preocupações e objetivos das organizações, não se pode perceber a mesma proposta entre os conceitos anteriores e as respostas. Os respondentes percebem que as empresas têm outras preocupações e objetivos (consumo consciente e responsável dos recursos naturais; qualidade dos produtos/serviços uso de tecnologias limpas; atendimento das necessidades dos clientes). Neste sentido, no contexto das empresas da região Oeste de Santa Catarina, 43,15\% dos respondentes consideram que existe maior enfoque para o desempenho econômico-financeiro por parte das empresas, $29,61 \%$ indicam que existe apenas a preocupação com a imagem mercadológica e 14,96\% dos 
respondentes indicam que não percebem a preocupação por parte das empresas com a sustentabilidade.

Observando as percepções dos acadêmicos, percebe-se que existe uma lacuna entre o discurso teórico/compreensão adequada sobre o tema, e as práticas das organizações empresariais. E embora teoricamente tenha ocorrido uma ênfase quanto à abordagem ambiental, na análise das percepções das práticas empresariais a ênfase percebida é para o contexto econômico-financeiro.

Destaca-se neste sentido a preocupação em aliar o desenvolvimento econômico e social com a adequada preservação dos recursos naturais, nas diversas áreas do conhecimento, tendo em vista o papel de formadores de opinião e de profissionais que se inserem nas organizações empresariais, visando possibilitar avanços e melhorias na inserção de práticas e ações sustentáveis de curto e longo prazo.

De modo geral, os resultados evidenciam a importância de discussões e avanços no meio acadêmico, em prol de ações e práticas empresariais que remetam a efetividade da sustentabilidade, no contexto da minimização dos efeitos e danos causados pelas atividades empresariais ao meio ambiente e a sociedade de modo geral.

Ainda, destaca-se a relevância das discussões e da compreensão acerca da temática sustentabilidade, visando promover reflexões na sociedade e especialmente no meio acadêmico, sobre o papel das instituições de ensino neste processo na formação de cidadãos conscientes, éticos e socialmente responsáveis.

\section{REFERÊNCIAS}

ALBARELLO, E. P. As transformações recentes na cadeia suinícola e suas consequências no desenvolvimento local: o caso do médio alto Uruguai Gaúcho. Ijuí, 2011, 88 f.

Dissertação de Mestrado. Universidade Regional do Noroeste do Estado do Rio Grande do Sul, Programa de Pós-Graduação Stricto Sensu em Desenvolvimento. Ijuí, 2011.

ALMEIDA, F. O bom negócio da sustentabilidade. Rio de Janeiro: Nova Fronteira, 2002.

ANGLADE, J. Agriculture durable et écologie: les indicateurs de durabilitè de la IDEA. Mèmorie de maîtrese de biologie dês organismes à L'Université d'Orsay (Paris-Sud XI), 1999.

BACALLAN, J. J. Greening the supply chain. Business and Environment, v. 6, n. 5, p. 11$12,2000$. 
BACHA, M. L.; SANTOS, J.; SCHAUN, A. Considerações teóricas sobre o conceito de sustentabilidade. In: Simpósio de Excelência em Gestão e Tecnologia- SEGeT, 7, 2010. Anais... Resende: SEGeT, 2010.

BANSAL, P. Evolving sustainability: a longitudinal study of corporate sustainable development. Strategic Management Journal, v. 26, p. 197-218, 2005.

BARIN-CRUZ, L; PEDROZO, E.; MARTINET, A. C. Estratégia de Desenvolvimento Sustentável: Integração Matriz/Filial numa Multinacional Siderúrgica Europeia. Revista Eletrônica de Administração - REAd, v. 13, p. 1-22, 2007.

CAMPOS, S. A. P.; ESTIVALETE, V. F. B.; MACHADO, M.S. Perspectivas da sustentabilidade e a relação com os stakeholders: um estudo envolvendo uma rede horizontal do segmento do varejo. In: ENCONTRO NACIONAL DE GESTÃO EMPRESARIAL E MEIO AMBIENTE - ENGEMA, Porto Alegre, 2008. Anais... Porto Alegre, 2008.

CLARO, P. B. O.; CLARO, D. P.; AMÂNCIO, R. Entendendo o conceito de sustentabilidade nas organizações. Revista de Administração, v. 43, n.4, p. 289-300, 2008.

COSTA, T.; SANTOS, S. S. Organizações da sociedade civil e as construções teóricas contemporâneas acerca da sustentabilidade. Cadernos Gestão Social, v. 2, n. 1, p. 105-120, 2009.

ELKINGTON, J. Cannibals with forks. The Triple Botton Line of 21 st Century Business. Filadélfia: New Society, 1998. 488p.

EPSTEIN, M. J.; ROY, M. J. Sustainability in Action: identifying and measuring the key performance drivers. Long Range Planning, v. 34, n. 5, p. 585-604, 2001.

KRUGER, S. D.; PFITSCHER, E. D.; UHLMANN, V. O.; PETRI, S. M. Sustentabilidade Ambiental: estudo em uma Instituição de Ensino Catarinense. Sociedade, Contabilidade e Gestão, v. 8, n. 1, p. 98-112, 2013.

MARZALL, K., ALMEIDA, J. Indicadores de sustentabilidade para agroecossistemas: estado da arte, limites e potencialidades de uma nova ferramenta para avaliar o desenvolvimento sustentável. Cadernos de Ciência \& Tecnologia, v. 17, n.1, p .41-59, 2000.

MEBRATU, D. Sustainability and sustainable development: historical and conceptual review. Environmental Impact Assessment Review, v. 18, n. 6, p. 493- 520, 1998.

MELO, L. E. L. de; CÂNDIDO, G. A. O Uso do método IDEA na avaliação de sustentabilidade da agricultura familiar no Município de Ceará-Mirim - RN. Revista de Administração, Contabilidade e Sustentabilidade, v. 3, n. 2, p. 1-19, 2013.

MOTA, C. R. As principais teorias e práticas de desenvolvimento. In: BURSTYN, Marcel (Org.). A difícil sustentabilidade: política energética e conflitos ambientais. 1 ed. Rio de Janeiro: Garamond, 2001, p. 27-40. 
RUSSO, M. V.; FOUNTS, P. A. A resource-based perspective on corporate environmental performance and profitability. Academy of Management Journal, v. 40, n. 3, p. 534-559, 1997.

TREVISAN, M.; MADRUGA, L. R.R.G.; BLOCK, A. S.; VICENTINI, M. M. Trabalhando as dimensões social, ambiental e econômica da sustentabilidade: estudo de caso em um rodeio internacional. In: ENCONTRO NACIONAL DE GESTÃO EMPRESARIAL E MEIO AMBIENTE - ENGEMA, Porto Alegre, 2008. Anais... Porto Alegre, 2008.

TRIGO, A. G. M.; LIMA, R. S. X.; DE OLIVEIRA, D. M. Índice de sustentabilidade socioambiental no ensino. Revista de Administração da UFSM, v. 7, p. 07-22, 2014.

UNITED NATIONS WORLD COMMISSION ON ENVIRONMENT AND DEVELOPMENT -WCED. Our common future, Oxford University Press, 1987.

ZAMBERLAN, J. F.; BORTOLOTTO, R. P.; RAMOS, J. P.; CABRAL, H.; JESUS, G.M.; LEÃO, D.; FRIZZO, K. A sustentabilidade no ensino técnico em administração: currículo oficial ou oculto. HOLOS, v. 31, n. 1, p. 214-226, 2015. 